\title{
Resource limitation in a competitive context determines complex plant responses to experimental resource additions
}

\author{
Caroline E. Farrior,${ }^{1,5}$ David Tilman, ${ }^{2}$ Ray Dybzinski, ${ }^{1}$ Peter B. Reich, ${ }^{3,4}$ Simon A. Levin, ${ }^{1}$ \\ and Stephen W. Pacala ${ }^{1}$ \\ ${ }^{1}$ Department of Ecology and Evolutionary Biology, Princeton University, Princeton, New Jersey 08544 USA \\ ${ }^{2}$ Department of Ecology, Evolution, and Behavior, University of Minnesota, St. Paul, Minnesota 55108 USA \\ ${ }^{3}$ Department of Forest Resources, University of Minnesota St. Paul, Minnesota 55108 USA \\ ${ }^{4}$ Hawkesbury Institute for the Environment, University of Western Sydney Penrith, New South Wales 2751 Australia
}

\begin{abstract}
Almost all models of plant resource limitation are grounded in either one or both of two simple conceptual models: Liebig's Minimum Hypothesis (LMH), the idea that plants are limited by the resource in shortest supply, and the Multiple Limitation Hypothesis $(\mathrm{MLH})$, the idea that plants should adjust to their environment so that all essential resources are equally limiting. Despite the differences in their predictions, experiments have so far failed to discriminate between them. In a simple factorial nitrogen and water addition experiment in a Minnesota grassland, we observed shifts in allocation that, as in previous studies, are not all explained by a single theory. We found that leaf biomass responded positively to nitrogen additions but did not respond to water additions. We found that fine-root biomass increased in response to water additions, but only at low nitrogen levels, and that fine-root biomass decreased in response to nitrogen additions, but only at high water levels.

To understand these responses we built a physiologically based model of plant competition for water, nitrogen, and space to predict plant allocation to fine roots and leaves. Critically, we include in our model the inherent variability of soil moisture and treat light, water, and nitrogen as resources with distinct mechanistic roles. Experimental results showed that plants were nitrogen and water limited. The model explains the experimental results, under conditions of co-limitation, as follows. Foliage increases with nitrogen additions but not water additions because leaf construction is constrained by nitrogen uptake. When water is added, plants spend a larger fraction of the growing season limited by light (and effectively nitrogen) than by water. Thus, water additions cause fine-root biomass to increase because of the increased importance of nitrogen limitation. The response of fine-root biomass to water additions decreases with nitrogen additions because these additions reduce nitrogen limitation. In general, our results are explained by sequential resource limitation. The rate of carbon assimilation may be limited by a single resource at any one moment, but the identity of the limiting resource(s) changes throughout the growing season.
\end{abstract}

Key words: Liebig's law of the minimum; multiple resource limitation hypothesis; nitrogen; plant competition; resource limitation; water.

\section{INTRODUCTION}

Scarcity of resources limits the productivity of plants, which creates incentives for competition and shapes the composition of, and interactions within, a community. As climate changes, the relative availabilities of different resources in communities may shift and play a critical role in determining how plant communities respond to climate change (Sinclair 1992, Oren et al. 2001, Luo et al. 2004, Reich et al. 2006). Understanding how resource availabilities influence plant communities is thus more important than ever.

Manuscript received 10 September 2012; revised 15 April 2013; accepted 7 May 2013. Corresponding Editor: A. M. de Roos.

${ }^{5}$ E-mail: cfarrior@princeton.edu
Almost all models of plant-essential resource limitation are grounded in either one or both of two simple conceptual models: Liebig's law of the minimum and optimal foraging for essential resources (e.g., Chapin 1980, Tilman 1982, Bloom et al. 1985, Gleeson and Tilman 1992, Harpole et al. 2011). Liebig's law of the minimum (Liebig's Minimum Hypothesis, LMH) is the idea that because it is unlikely that an environment will supply resources in the exact proportions that plants require, a plant will always be limited by a single resource (van der Ploeg et al. 1999). This idea was developed to understand agricultural systems, but was quickly adopted by community ecologists, and is still used today (e.g., Danger et al. 2008, Agren et al. 2012). However, several ecologists have pointed out that if a plant is limited by a single resource, it is by definition, at that moment, overinvesting in the uptake of all other essential resources. Strategic plants should adjust 
uptake to maintain limitation by all essential resources (Multiple Limitation Hypothesis, MLH [Tilman 1982, Bloom et al. 1985, Chapin et al. 1987]). These two theories make contradictory predictions for plant communities: LMH predicts that all communities should be limited by a single resource and only respond to changes in that resource whereas MLH predicts that plants should respond to any essential resource addition by decreasing their investment in uptake of that resource, making limitation by multiple resources the norm. Although this seems like the perfect opportunity for an experiment to settle a theoretical dispute, decades of resource-addition experiments leave us with support for both theories and few generalizations about the conditions that determine when one or the other is applicable (e.g., Aerts et al. 1991, Gedroc et al. 1996, Kaspari et al. 2008).

Several factors may help to explain the difficulty in finding a general theory of plant limitation (Rubio et al. 2003, Danger et al. 2008, Harpole et al. 2011). The availability of two or more resources may be physically tied together (e.g., water increasing microbial rates of nitrogen mineralization [Schimel et al. 1996]). Investment in a single structure may increase the uptake of several different resources (i.e., leaves capture light and take in $\mathrm{CO}_{2}$ ). Essential resources, which determine limitation, may be used for nonessential functions (i.e., a specific resource may be critical for one process but substitutable in other functions). Communities may include individuals with differing resource requirements but with access to the same resource pools.

Perhaps a less-appreciated role of resource limitation is that it creates incentives for plants to over-invest in resource capture. Here, by "over-invest," we mean a phenomenon in which plants invest in resource capture at levels that would be suboptimal for the productivity of a plant in isolation but pay off for the plant in competition with others, e.g., investment in height growth for light capture and investment in fine roots for belowground resources (Givnish 1982, Iwasa et al. 1984, King 1990, Falster and Westoby 2003, Craine 2006, Dybzinski et al. 2011, Farrior et al. 2013, McNickle and Dybzinski 2013). The negative effect of competition on whole-community productivity has been elegantly demonstrated in several experiments where competition was manipulated (e.g., Maina et al. 2002, Montgomery et al. 2010, Semchenko et al. 2010). However, the role of competitive over-investments has been largely overlooked in resource limitation theory and adds a level of complication to both LMH and MLH perspectives.

How and whether any or all of these complications influence resource limitation depends on specific details of the resource: availability, method of plant uptake, and dependence of plant fitness on uptake. In an effort to incorporate these details, we focus on two essential resources: water, and nitrogen. Both water and nitrogen are essential resources that commonly limit plant growth, evidenced by the use of irrigation and nitrogen rich fertilizer in agricultural fields all over the globe (Postel et al. 1996, Vitousek et al. 1997).

In most plant communities, water availability fluctuates over timescales that are shorter than a plant's ability to shift its allocation strategy. Within a single hot summer day, a plant can move from water saturation in the morning to severe water limitation in the middle of the day and return to water saturation before it shuts off photosynthesis in the evening (Slatyer 1967; cited in Larcher [2003]). With a simple model of variable water availability, Farrior et al. (2013) found that trees in competition for water and light depend critically on the timing, and not just the amount, of water availability. The model predicts that the amount of time that plants are water saturated and how much water they have on average during water limitation, both indices of water availability, have opposite effects on the dominant allocation strategy. The competitive plants have allocation strategies that balance the benefits of competition for water during water limitation with competition for light during water saturation.

Because of the variability of water availability, it is likely that the resources that limit plants shift identity throughout the growing season, adding another complication to the LMH and MLH debate. Indeed, over the course of the entire growing season, limitation by light, water, and nitrogen may be the norm for several reasons. First, plants shade themselves with their own leaves, making their lowest leaves light limited. Second, water likely moves from saturating levels immediately after rain to limiting levels during long periods between storms (or even during hot periods within a day). Third, nitrogen often limits the number of leaves that plants can physically build.

In this paper, we seek to understand the interactions of light, water, and nitrogen limitation in plant communities and their effects on plant allocation strategies. We first present the results of a factorial resource addition experiment in a water and nitrogenlimited environment. Like other such experiments (e.g., Aerts et al. 1991, Gedroc et al. 1996, Kaspari et al. 2008), we find pieces of evidence that contradict basic predictions from both LMH and MLH. We present a model, which includes aspects of LMH and MLH, but also includes water variability and the influence of interstrategy competition among plants. These findings lead to new predictions that are consistent with the data and provide a novel conceptual understanding of limitation by light, water, and nitrogen in plants.

\section{Nitrogen and Water Addition Experiment}

We planted $369 \times 9 \mathrm{~m}$ plots on disked soil on a Minnesota sandplain in 1994 with 32 grassland native or naturalized perennial species including: nine forbs, eight legumes, seven $\mathrm{C}_{3}$ grasses, and eight $\mathrm{C}_{4}$ grasses. A full 
species list for the experiment is available online (see Other Cedar Creek Data: E248). ${ }^{6}$

From 2007 to 2010, these plots were treated with all combinations of three nitrogen $(0,7$, and $14 \mathrm{~g}$ $\mathrm{NH}_{4} \mathrm{NO}_{3} \cdot \mathrm{m}^{-2} \cdot \mathrm{yr}^{-1}$ applied at the beginning of the growing season) and two water treatments (ambient and elevated). Elevated water treatments were administered manually with sprinklers in an attempt to evenly add $2 \mathrm{~cm}$ per week to soil, a doubling of average growing season rainfall for the area.

Two $10 \mathrm{~cm}$ wide by $6 \mathrm{~m}$ long samples of aboveground biomass were clipped from each plot during the first week of September 2010, near peak biomass. Sampling time was chosen to be at the point of maximal productivity for an accurate representation of leaf and fine-root biomass in the plots. All biomass from $1 \mathrm{~cm}$ above the soil was collected. Biomass from the first strip was left unsorted and dried together, whereas biomass from the second strip was separated while fresh into leaf, reproductive, and structural biomass. Material from each of these categories was dried to constant mass and weighed. All biomass with photosynthetic potential was counted as leaf biomass. Reproductive biomass consisted of inflorescences together with any structural biomass that did not also support leaves. All other nonphotosynthetic aboveground biomass was counted as structural biomass. See Appendix A for examples. It should be noted that this one-time sampling was meant to capture plant investment in leaf and fine-root biomass. Measurements of reproductive biomass will be significant underestimates of the total investment in reproductive biomass throughout the year because many species flower earlier or later in the season.

Samples of belowground biomass were harvested from the strips taken in the aboveground harvest. Within the first sampled strip, we collected six $5 \mathrm{~cm}$ diameter by $30 \mathrm{~cm}$ deep soil cores from evenly spaced locations within the strip of clipped aboveground biomass. These samples were washed of soil on a 1 $\mathrm{mm}$ screen, dried to constant biomass, and weighed. Within the second sampled strip, $125 \mathrm{~cm}$ diameter by 30 $\mathrm{cm}$ deep soil cores were taken. These roots were washed on the screen as well, but were sorted to fine $(<1 \mathrm{~mm}$ diameter), coarse roots ( $>1 \mathrm{~mm}$ diameter), and root crowns (biomass at or below the soil surface where the roots join the stem) before being dried and weighed. All fine roots were processed after drying to remove any remaining soil and then dried again.

Analyses of total biomass, aboveground biomass, and belowground biomass include all $1.2 \mathrm{~m}^{2}$ of aboveground biomass and all 18 soil cores. Analyses of the component parts of the biomass come from the single $0.6-\mathrm{m}^{2}$ strip and 12 soil cores. Statistics were performed with $\mathrm{R}$ (version 2.9.2; R Development Core Team 2009) and JMP (v10; SAS Institute 2012). Nitrogen and water

\footnotetext{
${ }^{6}$ http://www.cbs.umn.edu/cedarcreek/research/data
}
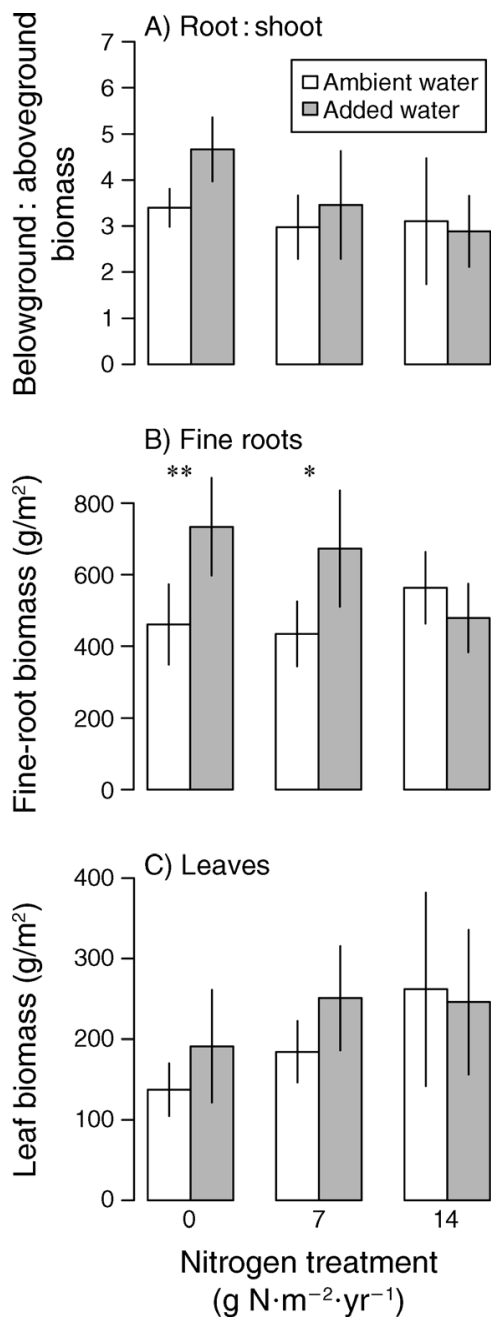

FIG. 1. Responses of prairie plants to nitrogen and water additions: (A) root:shoot ratio measured as total belowground : aboveground dry mass biomass per unit ground area, (B) fine-root biomass per unit ground area, and (C) leaf biomass per unit ground area are the biomass components that explain the total response in aboveground and belowground responses separately (Table 1 ). Error bars indicate \pm SD.

$* P<0.05 ; * * P<0.01$, for effect of the water treatment given a particular nitrogen treatment (Tukey post-hoc, $N=12$ for each).

treatments were treated as factors in the analysis. Significance levels are indicated as $* P<0.05, * * P<$ $0.01, * * * P<0.001$, throughout.

\section{EXPERIMENTAL RESULTS}

Aboveground plant biomass increased significantly with nitrogen additions but not water additions. Data from the separated aboveground biomass strip show that this pattern is due to changing leaf biomass (Fig. 1C, Table 1). Structural biomass did not respond significantly to either resource addition. Reproductive biomass, measured as reproductive biomass on the plants at the time of harvest, significantly decreased 
TABLE 1. Prairie biomass component responses to nitrogen and water additions.

\begin{tabular}{lcccc}
\hline \hline & \multicolumn{3}{c}{ Effect size } & \\
\cline { 2 - 4 } \multicolumn{1}{c}{ Component } & Nitrogen & Water & Nitrogen $\times$ water & Model $R^{2}$ \\
\hline Aboveground & $44.55^{*}$ & +16.41 & -21.62 & 0.25 \\
Reproductive & -1.21 & $-5.81^{*}$ & +1.55 & 0.17 \\
Leaf & $+41.97^{*}$ & +17.41 & -25.36 & $0.30^{*}$ \\
Structural & +12.76 & -1.81 & -4.60 & 0.12 \\
Belowground & -22.56 & $+143.37^{* * *}$ & $-155.89^{* *}$ & $0.54^{* * *}$ \\
Root-crown & +7.49 & +0.70 & -33.69 & 0.05 \\
Coarse-root & +1.47 & -6.39 & -15.58 & 0.11 \\
Fine-root & -36.18 & $+71.17^{* *}$ & $-113.41^{* *}$ & $0.51^{* * *}$ \\
Below : aboveground & $-0.42^{*}$ & +0.26 & -0.37 & $0.34^{*}$ \\
Total & +22.00 & $+159.78^{* * *}$ & $-177.51^{* *}$ & $0.50^{* * *}$ \\
\hline
\end{tabular}

Notes: Each row represents a single two-way analysis of variance. Water and nitrogen treatments are treated as factors (for each row, $N=36, \mathrm{df}=2,1$, and 2 for nitrogen, water, nitrogen $\times$ water interaction, respectively). A plus sign indicates a positive effect, a minus sign indicates a negative effect. Main effects, interaction effects, and the model $R^{2}$ estimated from a generalized linear model for each are provided. Note that effect sizes for each component biomass do not add up perfectly to those for the aggregate measures (aboveground, belowground, and total) because aboveground, belowground, and total biomass includes data from a second clip strip that was not sorted into the component parts.

$* P<0.05 ; * * P<0.01 ; * * * P<0.001$.

with water additions and did not respond to nitrogen additions.

Belowground plant biomass responded to both water and nitrogen additions. Separated belowground biomass again shows that the total pattern is driven by changes in the resource gathering tissues, fine roots. Coarse-root and root-crown biomass did not respond significantly to the resource additions. Total belowground and fine-root biomass increased significantly with water additions. A significant interaction of the water and nitrogen additions reveal two, more subtle, patterns: (1) fine-root biomass increased with water additions, but only at low nitrogen levels (effect of water addition under ambient, 7 $\mathrm{g} \mathrm{N} \cdot \mathrm{m}^{-2} \cdot \mathrm{yr}^{-1}$, and $14 \mathrm{~g} \mathrm{~N} \cdot \mathrm{m}^{-2} \cdot \mathrm{yr}^{-1}$, respectively [Tukey post-hoc test, $N=12$ for each] is $+272 * *,+239 *$, and $-84.48 \mathrm{~g} / \mathrm{m}^{2}$ [plus sign indicates an increase and minus sign indicates a decrease]) and (2) fine-root biomass decreased with nitrogen additions but only at high water levels (effect of $14 \mathrm{~g} \mathrm{~N} \cdot \mathrm{m}^{-2} \cdot \mathrm{yr}^{-1}$ under ambient and added water levels, respectively [Tukey post-hoc, $N=12$ for each] is +103 and $-255^{* *} \mathrm{~g} / \mathrm{m}^{2}$ ).

Like several other simple resource-addition experiments (e.g., Aerts et al. 1991, Gedroc et al. 1996, Kaspari et al. 2008), we obtained a constellation of confusing results. Neither LMH nor MLH is sufficient to explain all of the significant results. Plants responded to both water and nitrogen additions, showing the plants were not limited by a single nutrient, a result not predicted by LMH. Plants responded to the addition of a belowground resource, water, by increasing their investment belowground, a result that contradicts MLH. Moreover, the interaction between the effects of water and nitrogen additions on fine-root biomass suggests that plants become water saturated at high levels of nitrogen. This pattern is consistent with substitutable resources (a possibility for water and nitrogen [Wright et al. 2003]), but is contradicted by the opposing responses to water and nitrogen at the lower addition levels.

We now develop a model that draws heavily on LMH and MLH, but adds variability in water availability, and most importantly, competitive optimization of allocation.

\section{A Model of Plant Competition for Water, Nitrogen, and Space \\ Model overview}

Here we describe a model of competition for water, nitrogen and space among plants with different allocation strategies. The model borrows heavily from forest models of competition for light and nitrogen (Dybzinski et al. 2011) and light and water (Farrior et al. 2013) with modifications for prairie plants.

In brief, we determine the competitive-dominant strategy of allocation of photosynthates among three pools: leaves, fine roots, and reproductive biomass. We imagine these plants as individuals, each occupying the same amount of space and spending a negligible amount of their lifetime as growing juveniles. Adult plants use their photosynthates for the respiration and maintenance of leaves and fine roots, and spend the rest on reproduction. We assume that aboveground plants do not shade one another whereas belowground their roots share access to common resource pools of water and nitrogen. For this system, it has been shown that belowground competition plays a much stronger role than aboveground competition in plant productivity (Wilson and Tilman 1991). However, these strict assumptions about plant territoriality are relaxed in Appendix B, which demonstrates that they are not critical to the qualitative predictions of the model. 
What is critical is our assumption that light, water, and nitrogen are distinct resources that have different functions within the plant. Light is intercepted by leaves and used in photosynthesis. Leaves are self-shading; each successive leaf layer absorbs less light and, when light falls below the threshold required to saturate the photosynthetic machinery, does less photosynthesis than the layer above it. Water is transpired by the plant in exchange for the uptake of carbon dioxide. If there is not sufficient water to match the demand of the leaves, photosynthesis and transpiration are downregulated by stomatal closure until water supply matches demand. Nitrogen is used to build leaves and in the rest of the plant in processes that support the leaves. If nitrogen is in limiting supply, the amount of leaf biomass is constrained.

Not only do we model the basic differences in plant use of light, water, and nitrogen, but we also model the basic differences in plant competition above and belowground. Water and nitrogen are both taken up by fine roots belowground where they share access to resources with the rest of the individuals in the community. In addition, plants compete for space. When an individual dies, it is replaced with a randomly selected seed from the pool of seeds produced by all individuals in the community. Individuals that invest more in reproduction than other individuals will have more seeds in the pool and a higher chance of taking over this spot.

The payoff of investments in leaves, fine roots, and fecundity for an individual is determined by the other strategies present in the community. When a belowground resource is limiting, we assume that the plants are capable of taking all of it up. Therefore if one plant invests more in fine roots than another plant, it will get more water and nitrogen than the other plant. Similarly we assume that the empty sites left by individuals are always colonized by seeds, and thus the only way a plant can increase its chance of winning a vacant site is by increasing its fecundity relative to that of its competitors. To find the competitive dominant allocation strategy (i.e., the strategy we expect to dominate either through individual plasticity or species replacement), we derive the allocation strategy that when in monoculture cannot be invaded by any other. This is the evolutionarily stable strategy (ESS).

We limit our description and analysis to situations in which plants are light, water, and nitrogen limited (although all other combinations of limitation have been analyzed; C. E. Farrior, unpublished analyses). This turns out to be a common scenario in the model's parameter space and is the case most likely to help us understand the results of our experiment, which shows plant responses to both water and nitrogen. We assume photosynthesis is limited for part of the year by light and the rest of the year by water. We assume nitrogen limits the production of leaf biomass and thus effectively limits photosynthesis while plants are light limited.
The rest of this section provides the mathematical formulation of these processes with further biological justification and detail. Variables are also defined in Table 2 and units are given there.

\section{Individual plant physiology}

Because individuals of perennial grassland species can live for several decades (Adler et al. 2006), we assume the time it takes an individual to reach maturity and begin reproduction is much shorter than its expected lifetime. This makes the proportion of ground filled by immature individuals at any one time close to zero. Here we approximate it as precisely zero.

Each mature plant occupies the same amount of space. They do not grow (in the sense of occupying more space or of having a greater maximum biomass in each successive year), but invest photosynthates in the maintenance of leaves $(l)$ and fine roots $(r)$ and in reproduction $(f)$. That is, adult mass increases with $l$ or $r$ but all adults occupy the same amount of area. However, note that this model is equivalent to any in which individuals may be described by a characteristic investment in leaves and fine roots per unit area, and in which the plant fitness is proportional to the carbon left over after paying for the respiration and maintenance of leaves and fine roots.

At any one instant, the rate of carbon assimilation in a plant with a given amount of leaf biomass $l$ is either limited by light or by water. If carbon assimilation is light limited, plants operate photosynthesis at a rate determined by the light that their leaves can capture $\left(A_{\mathrm{L}}\right)$. Within a plant, each leaf layer has less light than the layer above it due to self-shading. The total number of layers is given by $l / \eta$, where $\eta$ is the leaf mass per unit leaf area, assumed to be constant. The light level falls off exponentially through the plant at a rate $k$ with the number of leaf layers $\left(L_{0} \exp [-k(l / \eta)]\right.$, where $L_{0}$ is the light at the top of the plant). We use a simplified model of photosynthesis where photosynthesis is proportional to light level (by $\alpha_{\mathrm{f}}$ ), up to a maximum rate $V$. We assume that plants have enough leaf layers such that not all are operating at the maximum rate $(l>$ $\left.(\eta / k) \ln \left[\alpha_{\mathrm{f}} L_{0} / V\right]\right)$ :

$$
A_{\mathrm{L}}(l)=\frac{V}{k}\left[1+\ln \left(\frac{\alpha_{\mathrm{f}} L_{0}}{V}\right)-\frac{\alpha_{\mathrm{f}} L_{0}}{V} e^{-k(l / \eta)}\right] .
$$

If carbon assimilation is water limited, plants operate photosynthesis at a lower level $\left(A_{\mathrm{W}}\right)$, limited by their water uptake. Water uptake is fine-root biomass $r$ multiplied by the conductance of fine roots to water $u_{\mathrm{W}}$ and the water available in the soil $W$ :

$$
A_{\mathrm{W}}(r, W)=\omega r u_{\mathrm{W}} W
$$

where $\omega$ is the intrinsic water-use efficiency. See Appendix C for an illustration of Eqs. 1 and 2.

To capture the variability in water availability, we assume plants spend a portion of the growing season saturated with water and the rest of the time limited by 
TABLE 2. Description of model variables.

\begin{tabular}{|c|c|c|}
\hline Variable & Definition & Units \\
\hline$s$ & size of the community & $\mathrm{m}^{2}$ \\
\hline$r$ & fine-root biomass & $\mathrm{g} \mathrm{C} / \mathrm{m}^{2}$ \\
\hline$l\left(r^{\prime}, N(r)\right)$ & leaf biomass of individuals with strategy $r^{\prime}$, in monoculture of strategy $r$ & $\mathrm{~g} \mathrm{C} / \mathrm{m}^{2}$ \\
\hline$f\left(r^{\prime}, N(r), W(r)\right)$ & rate of seed production strategy $r^{\prime}$ in a monoculture of strategy $r$ & seeds $\cdot \mathrm{m}^{-2} \cdot \mathrm{yr}^{-1}$ \\
\hline & leaf mass per unit leaf area & $\mathrm{g} \mathrm{C} / \mathrm{m}^{2}$ \\
\hline$N_{0}$ & nitrogen mineralization rate & $\mathrm{g} \mathrm{N} \cdot \mathrm{m}^{-2} \cdot \mathrm{yr}^{-1}$ \\
\hline$N$ & nitrogen availability & $\mathrm{g} \mathrm{N} / \mathrm{m}^{2}$ \\
\hline$u_{\mathrm{N}}$ & conductance of nitrogen from root to leaf & $\mathrm{m}^{2} \cdot \mathrm{g} \mathrm{C}^{-1} \cdot \mathrm{yr}^{-1}$ \\
\hline$L_{0}$ & photosynthetically active radiation & MJ PAR $\cdot \mathrm{m}^{-2} \cdot \mathrm{yr}^{-1}$ \\
\hline$k$ & exponential rate of light extinction by leaf layers & \\
\hline$\alpha_{\mathrm{f}}$ & leaf-level photosynthetic dependence on light level & $\mathrm{g} \mathrm{C} / \mathrm{MJ} \mathrm{PAR}$ \\
\hline$V$ & maximum photosynthetic rate & $\mathrm{g} \mathrm{C} \cdot \mathrm{m}^{-2} \cdot \mathrm{yr}^{-1}$ \\
\hline$q$ & fraction of the growing season spent in water saturation & \\
\hline$W_{0}$ & precipitation during water limitation & $\mathrm{m} / \mathrm{yr}$ \\
\hline$W$ & water availability & $\mathrm{m}^{3}$ water $/ \mathrm{m}^{2}$ surface \\
\hline$u_{\mathrm{W}}$ & conductance of water from root to leaf & $\mathrm{m}^{2} \cdot \mathrm{g} \mathrm{C}^{-1} \cdot \mathrm{yr}^{-1}$ \\
\hline$\omega$ & intrinsic water-use efficiency & $\mathrm{g} \mathrm{C} / \mathrm{m}$ \\
\hline$A$ & rate of carbon assimilation & $\mathrm{g} \mathrm{C} / \mathrm{yr}$ \\
\hline$A_{\mathrm{L}}$ & light-limited carbon assimilation & $\mathrm{g} \mathrm{C} \cdot \mathrm{m}^{-2} \cdot \mathrm{yr}^{-1}$ \\
\hline$A_{\mathrm{W}}$ & water-limited carbon assimilation & $\mathrm{g} \mathrm{C} \cdot \mathrm{m}^{-2} \cdot \mathrm{yr}^{-1}$ \\
\hline$c_{1}$ & carbon cost of leaf respiration and maintenance & 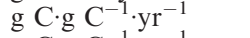 \\
\hline$c_{\mathrm{r}}$ & carbon cost of fine-root respiration and maintenance & $\mathrm{g} \mathrm{C} \cdot \mathrm{g} \mathrm{C}^{-1} \cdot \mathrm{yr}^{-1}$ \\
\hline$c_{\mathrm{f}}$ & carbon cost of seed production & $\mathrm{g} \mathrm{C} /$ seed \\
\hline & plant nitrogen maintenance per year per leaf biomass & $\mathrm{g} \mathrm{N} \cdot \mathrm{g} \mathrm{C}^{-1} \cdot \mathrm{yr}^{-1}$ \\
\hline$F\left(r^{\prime}, r\right)$ & fitness of strategy $r^{\prime}$ in the environment set by a monoculture of strategy $r$ & \\
\hline
\end{tabular}

Note: PAR is photosynthetically active radiation.

water. For convenience, we sum these such that plants spend $q$ fraction of the growing season water saturated and $1-q$ fraction of the growing season water limited. The total carbon assimilation over the growing season $(A)$ is then the time-weighted average of light-limited and water-limited carbon assimilation rates:

$$
A(r, l, W)=q A_{\mathrm{L}}(l)+(1-q) A_{\mathrm{W}}(r, W) .
$$

Each year, this carbon is used to pay for the costs of respiration and maintenance of the roots $c_{\mathrm{r}}$ and leaves $c_{1}$ as well as the cost of the plant's investment in reproduction $c_{\mathrm{f}}$. We assume these costs are proportional to the biomass of each component. Note that $c_{\mathrm{r}}$ and $c_{1}$ encompass the costs of respiration for as well as the costs of turning over all (as in leaves) or a portion (as in fine roots) of the plant biomass for a single year.

Only allocation patterns that balance the carbon assimilation over a growing season $(A)$ with these costs are physically possible. Thus,

$$
A(r, l, W) \equiv c_{\mathrm{r}} r+c_{1} l+c_{\mathrm{f}} f
$$

where $f$ is the seed production of the plant. This conservation of carbon within the plant constrains the set of feasible allocation strategies to two dimensions.

Here we assume that nitrogen is limiting, placing a second constraint on the feasible allocation strategies. Following Dybzinski et al. (2011) we assume that half of the nitrogen used by the plant each year is used to build leaves of fixed stoichiometry and that the remainder is used in other tissues with flexible stoichiometry. Because nitrogen uptake in natural systems is primarily limited by diffusion and mass flow, rather than uptake kinetics (Chapin 1980, Raynaud and Leadley 2004, Craine et al. 2005), we assume that relative differences in fine-root mass affect uptake but that root stoichiometry does not affect uptake ( $u_{\mathrm{N}}$ is constant). In short, if nitrogen is in limiting supply, the leaf biomass of the plant is constrained by nitrogen uptake:

$$
l(r, N)=\frac{u_{\mathrm{N}} r N}{\rho}
$$

where nitrogen uptake is fine-root biomass $(r)$ multiplied by the conductance of fine roots to nitrogen $\left(u_{\mathrm{N}}\right)$ and by the nitrogen availability in the soil $(N)$. The variable $\rho$ is the amount of nitrogen needed by the plant per unit of leaf biomass per year.

Given resource availability, the constraints of carbon conservation and nitrogen limitation reduce the potential allocation strategy space to a single dimension. For convenience, we choose to follow the investment in fineroot biomass $(r)$ when defining allocation strategy. From resource availability and $r$, one can calculate the leaf biomass $l$ and investment in reproduction $f$ of the plant.

We describe the rest of the model in two steps: first we describe the environment created by a monoculture of individuals with allocation strategy defined by fine-root biomass $r$ (hence, strategy $r$ ). This environment includes all influences of the community of individuals on the resource availability to an individual: water availability $W$, nitrogen availability $N$, and competition for sites, measured by seed production $f$. Second, we describe the invasion potential of an individual with a different 
allocation strategy, $r^{\prime}$, in this environment. With this framework, we then find the allocation strategy that, when in monoculture, cannot be invaded by any other. The strategy $r^{*}$, if it exists, is the evolutionarily stable strategy (ESS) and predicted to be the dominant strategy in the community.

Note, different allocation strategies ( $r$ 's) are most easily thought of as different species. In reality however, an individual plant may have the plasticity to adopt the new ESS strategy following an environmental change. Thus differences among strategies are most generally thought of as different phenotypes that plants may achieve through species replacement or individual plasticity.

\section{The environment created by a monoculture of a single strategy, $r$}

To find the strategy that cannot be invaded, we must first examine how an allocation strategy affects the environment experienced by other individuals: nitrogen availability, water availability, and competition for sites.

Nitrogen availability $(N)$ is the result of inputs from the environment and the uptake of plants. Nitrogen comes in at constant nitrogen-mineralization rate $\left(N_{0}\right)$, assumed to be independent of the allocation strategies of the plants in the community. Plants take up nitrogen at a constant rate $\left(u_{\mathrm{N}}\right)$ proportional to their investment in fine roots $(r)$. For nitrogen-limited plants, fine roots are relatively efficient at nitrogen uptake and leakage of nitrogen from the system is small. Here we assume leakage is zero.

Because there is considerable overlap in inter-individual fine roots (Frank et al. 2010) and because mineral nitrogen is relatively mobile, we assume the fluxes in and out of the available nitrogen pool are well mixed within the community of size $s$. If the environment is filled with individuals with $r$ fine-root biomass, the change in nitrogen availability over time is then

$$
\frac{\mathrm{d} N}{\mathrm{~d} t}(r)=\frac{s N_{0}-s u_{\mathrm{N}} r N(r)}{s} .
$$

Nitrogen availability $N$ reaches an equilibrium when

$$
N(r)=\frac{N_{0}}{u_{\mathrm{N}} r} .
$$

Water availability is also the result of inputs from the environment and the uptake of plants. We use a simplified model of rainfall. Rainfall comes in as a constant drizzle that switches between two levels: one that is high enough for water saturation, and one that is low enough for water limitation. When plants are water saturated, their photosynthesis does not depend on water availability and there is no competition for water. During water limitation, water comes in at a constant rate of drizzle $\left(W_{0}\right)$, and plants take up water at a constant rate proportional to their investment in fine roots $\left(u_{\mathrm{W}}\right)$. If the environment is filled with individuals with $r$ fine-root biomass, the change in water availability over time is then

$$
\frac{\mathrm{d} W}{\mathrm{~d} t}(r)=\frac{s W_{0}-s u_{\mathrm{W}} r W(r)}{s} .
$$

Water availability during water limitation $(W)$ reaches an equilibrium when

$$
W=\frac{W_{0}}{u_{\mathrm{W}} r} .
$$

Site availability is determined by the fecundity of individuals with allocation strategy $r$, the number of seeds an invader will have to compete with in a lottery to occupy new sites. To find this, we solve Eq. 4 evaluated at $N(r)$ and $W(r)$ of Eqs. 7 and 9 for $f$ :

$$
\begin{gathered}
f(r, N(r), W(r)) \\
=\frac{1}{c_{\mathrm{f}}}\left[q \frac{V}{k}\left(1+\ln \left[\frac{\alpha_{\mathrm{f}} L_{0}}{V}\right]-\frac{\alpha_{\mathrm{f}} L_{0}}{V} e^{-k\left(N_{0} / \eta \rho\right)}\right)\right. \\
\left.+(1-q) \omega W_{0}-c_{1} \frac{N_{0}}{\rho}-c_{\mathrm{r}} r\right] .
\end{gathered}
$$

\section{Expected fitness of an individual with strategy, $r^{\prime}$}

If an individual with the invading strategy has greater seed production than an individual of the resident strategy, $r$, it will slowly win ever more open sites, potentially taking over as resident. The competitive-dominant strategy (single-strategy ESS), if it exists, is one that creates an environment that no other strategy can invade.

An individual with allocation strategy $r^{\prime}$ invading an equilibrium monoculture of strategy $r$ has a seed production rate of $f\left(r^{\prime}, N(r), W(r)\right)$ (illustrated in Fig. 2):

$$
\begin{aligned}
f\left(r^{\prime}, N(r), W(r)\right) \\
\quad=\frac{1}{c_{\mathrm{f}}}\left[A\left(r^{\prime}, N(r), W(r)\right)-c_{1} l\left(r^{\prime}, N(r)\right)-c_{\mathrm{r}} r^{\prime}\right]
\end{aligned}
$$

where $A\left(r^{\prime}, N(r), W(r)\right)$ is the carbon assimilation and $l\left(r^{\prime}, N(r)\right)$ is the leaf biomass of a plant with allocation strategy $r^{\prime}$ in the environment set by individuals of allocation strategy $r$. Using equilibrium values of $N$ and $W$ with individuals of $r$ fine-root biomass (Eqs. 7 and 9), we find

$$
l\left(r^{\prime}, N(r)\right)=\left(\frac{r^{\prime}}{r}\right)\left(\frac{N_{0}}{\rho}\right)
$$

$$
\begin{aligned}
A\left(r^{\prime}, W(r), N(r)\right) & \\
=(1-q) \omega \frac{r^{\prime}}{r} W_{0}+q \frac{V}{k} & {\left[1+\ln \left(\frac{\alpha_{\mathrm{f}} L_{0}}{V}\right)\right.} \\
& \left.-\frac{\alpha_{\mathrm{f}} L_{0}}{V} e^{-k\left(r^{\prime} / r\right)\left(N_{0} / \eta \rho\right)}\right]
\end{aligned}
$$




$$
\begin{aligned}
f\left(r^{\prime}, N(r), W(r)\right) & \\
=\frac{1}{c_{\mathrm{f}}}\left[(1-q) \omega \frac{r^{\prime}}{r} W_{0}+q \frac{V}{k}\left(1+\ln \left(\frac{\alpha_{\mathrm{f}} L_{0}}{V}\right)\right.\right. & \left.\quad-\frac{\alpha_{\mathrm{f}} L_{0}}{V} e^{-k\left(r^{\prime} / r\right)\left(N_{0} / \eta \rho\right)}\right) \\
& \left.-c_{1}\left(\frac{r^{\prime}}{r}\right)\left(\frac{N_{0}}{\rho}\right)-r^{\prime}\right] .
\end{aligned}
$$

Because population growth rate is proportional to an individual's relative seed set, the fitness of the invading strategy is

$$
F\left(r^{\prime}, r\right) \propto \frac{f\left(r^{\prime}, N(r), W(r)\right)}{f(r, N(r), W(r))} .
$$

Using Maynard Smith and Price's (1973) and Maynard Smith's (1982) definition of an ESS (the competitive-dominant strategy that cannot be invaded once established), we define an ESS as a strategy $r^{*}$, which satisfies the following conditions:

$$
\forall r^{\prime} \neq r^{*}: F\left(r^{\prime}, r^{*}\right)<F\left(r^{*}, r^{*}\right)
$$

or

$$
F\left(r^{\prime}, r^{*}\right)=F\left(r^{*}, r^{*}\right) \text { and } F\left(r^{*}, r^{\prime}\right)>F\left(r^{\prime}, r^{\prime}\right) .
$$

We also verify that the ESS is convergence stable, meaning a community could arrive at them by successive invasions of individuals with small trait differences (Geritz et al. 1998; see Appendix D).

\section{Model Predictions}

For a light-, water-, and nitrogen-limited plant, the competitive-dominant (ESS) allocation strategy is

$$
\begin{aligned}
r^{*}= & (1-q) \frac{\omega W_{0}}{c_{\mathrm{r}}}+q \frac{\alpha_{\mathrm{f}} L_{0} \frac{N_{0}}{\rho \eta} e^{-k\left(N_{0} / \rho \eta\right)}}{c_{\mathrm{r}}} \\
& -\left(\frac{c_{1}}{c_{\mathrm{r}}}\right)\left(\frac{N_{0}}{\rho}\right)
\end{aligned}
$$

which in monoculture has leaf biomass

$$
l^{*}=\frac{N_{0}}{\rho} .
$$

Because we assume that (1) nitrogen is in limiting supply, (2) precipitation is sufficiently variable so that water is sometimes limiting and sometimes not, and (3) nitrogen is sufficiently common for the leaf biomass of plants to cause at least some self-shading, we find that the productivity, fine-root investment, and fecundity of the competitive (ESS) plants depends on all three resources: light, water, and nitrogen.

ESS fine-root biomass $\left(r^{*}\right)$ is the sum of three components (Eq. 17). The third component accounts for the carbon constraint on fine-root biomass caused by building leaves. It is the biomass of roots that could have been made and maintained if the plant did not have to pay to build and maintain its leaves (the carbon it takes to build and maintain $l^{*}, c_{1}\left[N_{0} / \rho\right]$, divided by the carbon cost of building and maintaining fine-root biomass, $c_{\mathrm{r}}$ ). Note that this term is independent of the time plants spend in water limitation $(1-q)$ or water saturation $(q)$.

The first two components of $r^{*}$ (Eq. 17) describe the influence of competition for water and nitrogen on $r^{*}$ and are weighted by the portion of time plants spend effectively limited by each. If plants spend a large portion of the growing season in water limitation ( $q$ is close to zero), competition for water, described by the first component, has a large influence on $r^{*}$. This component increases with $W_{0}$, the rate of water input during water-limitation and is independent of both the nitrogen mineralization rate $\left(N_{0}\right)$ and light $\left(L_{0}\right)$. If instead plants spend a large portion of the growing season in light limitation, effectively limited by their foliage and nitrogen uptake ( $q$ is close to one), competition for nitrogen, described by the second component has a large influence on $r^{*}$. This component increases linearly with light level $\left(L_{0}\right)$, increases and then decreases with nitrogen-mineralization rate $\left(N_{0}\right)$, and does not depend on the water input rate during water limitation $\left(W_{0}\right)$. Overall, water additions influence $r^{*}$ in two ways: first as a weight that determines the strength of competition for water vs. nitrogen, shifting the influence between the first and second components of Eq. 17 ( $q$, represented as a black "weight" in Fig. 3), and second as an influence on competition for water itself, where higher $W_{0}$ increases fine-root investment (represented by the height of the blue boxes in Fig. 3).

Although ours is a simple model of prairie plants, predictions for ESS fine-root and leaf investments are similar to those predicted from a forest dynamics model with individual-based height-structured competition. In particular, the dependence of the first component of Eq. 17 on $W_{0}$ and the second component on $N_{0}$ are the same as those presented in the cases of nitrogen saturation in forests (Farrior et al. 2013) and water saturation in forests (Dybzinski et al. 2011). We review the dependence of each on the belowground resource here.

When rainfall during water limitation $\left(W_{0}\right)$ increases, the competitive-dominant fine-root strategy increases linearly. Plants compete for water within a commons belowground, where the decrease in water availability due to uptake of an individual is shared by the group. Because individual fitness is the currency of selection, competitive plants invest in water uptake until the water availability is so low so that the costs of water uptake equal the benefits. If the currency of selection were instead plot-level productivity, plants would have a much lower investment in fine roots. As we have assumed no leakage of water during water-limitation, plants would only invest the infinitesimal amount needed to take up the water. Thus, competitive allocation reduces productivity, creating a tragedy of the commons (Hardin 1968). When the size of potential 


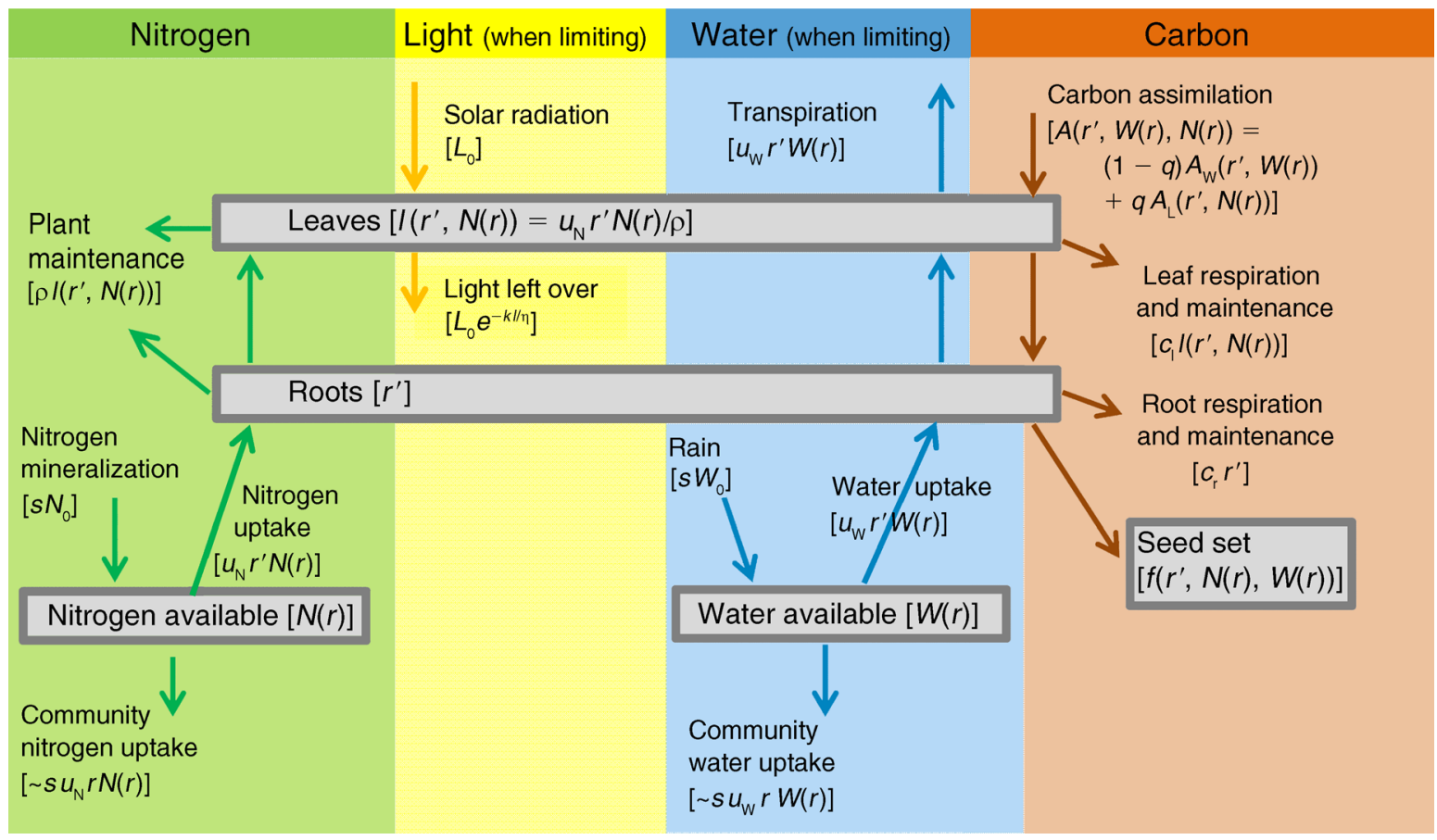

FIG. 2. All components of the model contributing to the investment in fecundity $\left[f\left(r^{\prime}, N(r), W(r)\right)\right]$ by an individual with strategy $r^{\prime}$ in a near-monoculture community of individuals with the fine-root strategy $r$. Light limits carbon assimilation when water is at sufficient levels ( $q$ fraction of the growing season), and water limits photosynthesis for the remaining fraction of the growing season $\left.(1-q) . A_{\mathrm{L}}\left(r^{\prime}, N(r)\right)=V / k\left[1+\ln \left(\alpha_{\mathrm{f}} L_{0}\right) / V\right)-\alpha_{\mathrm{f}} L_{0} / V e^{-k l\left(r^{\prime}, N(r)\right) / \eta}\right]$, and $A_{\mathrm{W}}\left(r^{\prime}, W(r)\right)=\omega r^{\prime} u_{\mathrm{W}} W$. See Table 2 for variable definitions.

benefits increase (as $W_{0}$ increases), the competitive investment in uptake $\left(r^{*}\right)$ increases so that the costs of uptake again equal the benefits to an individual (see Farrior et al. [2013] for further explanation).

Nitrogen, $N_{0}$, is also a resource taken up from within a commons. When $N_{0}$ increases at very low $N_{0}$ levels, competitive plants are predicted to increase their investment in fine roots, just as they do when $W_{0}$ increased. Nitrogen, however, is different from water because it is used by the plant to build leaves, the productivity of which depends on the leaf area already on the plant. After light availability falls below the threshold needed to operate at the maximum photosynthetic rate, each additional leaf has lower productivity than those already on the plant because of self-shading. Thus, each additional unit of nitrogen taken up by a plant yields an ever decreasing benefit, and the benefits of additional $N_{0}$ decrease as $N_{0}$ increases. So, in competition for nitrogen, plants initially respond positively to increasing $N_{0}$, but as $N_{0}$ increases beyond very low $N_{0}$ levels, $r^{*}$ decreases rapidly with continued $N_{0}$ additions. Several theories have predicted the decrease in fine roots with added nitrogen, but have focused on the carbon tradeoff between investment in fine roots and investment in leaves (e.g., Chapin 1980, Tilman 1988). The decreasing marginal returns of nitrogen uptake provide an additional mechanism that may explain decreases in fine-root biomass with $N_{0}$ additions.

Taking together the effects of nitrogen $\left(N_{0}\right)$ and water ( $q$ and $W_{0}$ ) on the competitive-dominant fine-root strategy $\left(r^{*}\right)$, we find two specific predictions for interactions between water and nitrogen. First, the influence of nitrogen on fine roots should be weaker when water availability is low. That is, when water is scarce, the time in water-saturation $(q)$ is low and the negative influence of $N_{0}$ on $r^{*}$ has less of an effect on the resultant fine-root biomass (compare columns of Fig. 3). Second, the influence of water $\left(q\right.$ and $\left.W_{0}\right)$ on fine-root biomass decreases with increased nitrogen availability $\left(N_{0}\right)$. The effect of water additions on $q$ and $W_{0}$ should be the same across nitrogen levels, but the fine-root biomass needed in competition for nitrogen should decrease. At low nitrogen levels, $r^{*}$ is higher than at high nitrogen levels. Adding water increases the weight of competition for nitrogen on $r^{*}$, thus exposing the effect of nitrogen on $r^{*}$. Thus the effect of water additions should become less positive or more negative on fineroot biomass as nitrogen increases (compare rows of Fig. 3).

\section{Discussion}

In our experiment, we found results, which, like several other resource addition experiments (e.g., Aerts 
et al. 1991, Gedroc et al. 1996, Kaspari et al. 2008), were not predicted by either Liebig's law of the minimum (LMH) or the optimal foraging/multiple limitation hypothesis (MLH). Plants responded to both nitrogen and water additions separately and together, violating Liebig's law of the minimum. Second, plants responded to water additions by increasing investment in fine roots, contradicting MLH.

These responses and almost all of the other significant empirical results were predicted by our model of plant competition for water, nitrogen, and space. Aboveground, leaf biomass responded positively to nitrogen additions but not to water additions, as predicted for nitrogen-limited plants. Belowground, the model predicts and the data show a significant interaction between water and nitrogen. Specifically, the positive response of fine roots to water additions weakened with nitrogen additions.

Our model predicts that the competitive fine-root strategy is a weighted average of the influences of competition for water and nitrogen. The weight is the fraction of time plants are limited by either resource, i.e., the fraction of time in water limitation and water saturation (and carbon assimilation is effectively nitrogen limited). When water is added, the competitive fineroot strategy is more heavily influenced by fine-root competition for nitrogen. This is evidenced experimentally by greater reduction of fine-root biomass in response to nitrogen additions with water additions (Fig. 3).

Looking at the interaction another way, we observed an increase in fine-root biomass in response to water additions, but only at low nitrogen levels. This increase in belowground biomass in response to the addition of a belowground resource can be explained by two different mechanisms. First, the increase may be the result of the predicted increase in the biomass with greater water availability during water limitation (the positive effect of $W_{0}$ on $\left.r^{*}\right)$. And/or the increase may be due to the greater weight of competition for nitrogen on fine-root biomass (increasing $q$ ), which is relatively high at low nitrogen levels. In both cases, the subsequent decrease in response with increasing nitrogen levels must be due to the decreasing nitrogen-limited fine-root ESS with greater nitrogen availability. These results are consistent with our theoretical prediction that plant responses to water during water limitation and to nitrogen are opposite: fine-root biomass should increase with water additions (assuming water is limiting at the time of additions) and decrease with nitrogen additions in all but the very lowest nitrogen levels (assuming nitrogen is limiting).

The mechanism responsible for this difference in predictions is the difference in the marginal returns of nitrogen and water uptake within a competitive context. Marginal returns are the net benefits of an additional, arbitrarily small unit of resource. The marginal returns of nitrogen uptake decrease with total nitrogen uptake, whereas marginal returns of water uptake remain constant with total water uptake. Nitrogen is used to build the engines of photosynthesis, the leaves. Because of self shading, the productivity of a leaf decreases as more leaves are placed above it, but the leaf costs remain the same (shade leaf plasticity moderates this phenomenon, but does not remove it). In contrast, water is a fuel of photosynthesis; when water is limiting, whole-canopy photosynthesis is simply proportional to water uptake.

A mechanism not included in our model is the potential positive biogeochemical interaction between water availability and nitrogen mineralization (Borken and Matzner 2009). There is a suggestion of this effect in the response of leaf biomass in the experiment. Leaf biomass increases with both water and nitrogen additions, although the response to nitrogen is much stronger than that of water (effect size of $42 \mathrm{~g} / \mathrm{m}^{2}$ vs. 17 $\mathrm{g} / \mathrm{m}^{2}$; Table 1). However, the interaction between water and nitrogen is negative, but not significant $(P=0.257$, Table 1). Belowground, fine-root biomass responds to water and nitrogen in opposite directions. If the biogeochemical interaction of water and nitrogen were driving the response, fine-root biomass should respond in the same direction to either resource. Thus, the observed leaf and fine-root biomass responses to water and nitrogen occurs in spite of any biogeochemical effect of water availability on nitrogen mineralization, not because of it.

Reproductive biomass decreased with water additions in the experiment. This is the only significant experimental response not predicted by our model. Recall that our sampling scheme was designed to capture standing biomass of leaves and fine roots accurately. The reproductive biomass we measured may not have accurately captured investment in reproductive biomass as we measured only the biomass attached to live plants (flowers, seeds, and their supports) during sampling in early September. Biomass produced and dropped earlier in the season is missing from our estimates. It is possible that water additions allowed plants to be reproductive earlier in the season and decreasing the reproductive biomass found on the plants in September. It is also possible that as long-lived perennial plants, reproduction output in any given year is not as tightly linked to resource availability as we assume for annual plants.

Our model is a simplified model of plant physiology that ignores several details of leaf physiology that could be important and are found in detailed models of leaf physiology (e.g., Collatz et al. 1991, Lloyd and Farquhar 1996, Evans and Poorter 2001, Farquhar et al. 2001). These include photorespiration, temperature dependencies of photosynthesis and respiration, the effect of vapor pressure deficit on stomates, variation in nitrogen allocation among leaves as a function of the level of shade, and variation among species in water-use efficiency. Any of these could affect our results quantitatively. However, their omission allowed us to derive qualitative results that we suspect are robust to the added details, including the way light, water and 

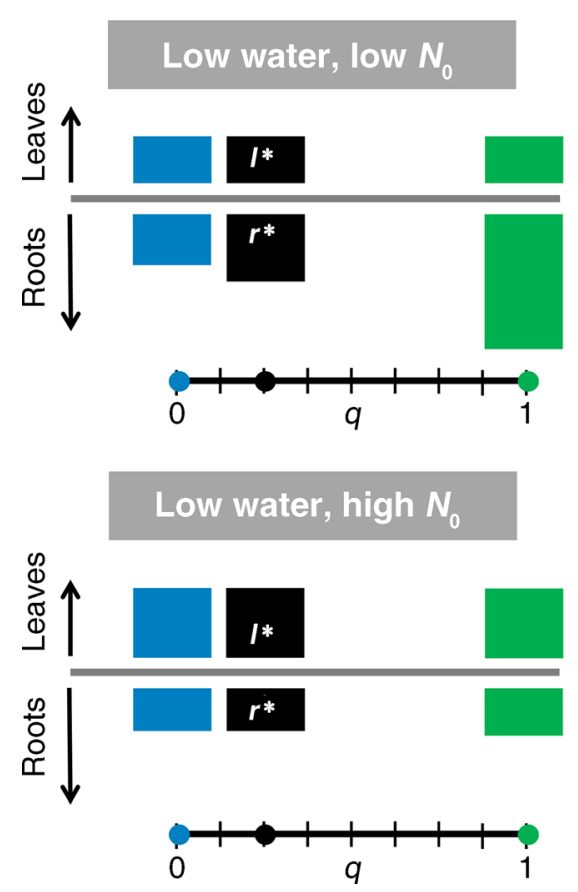

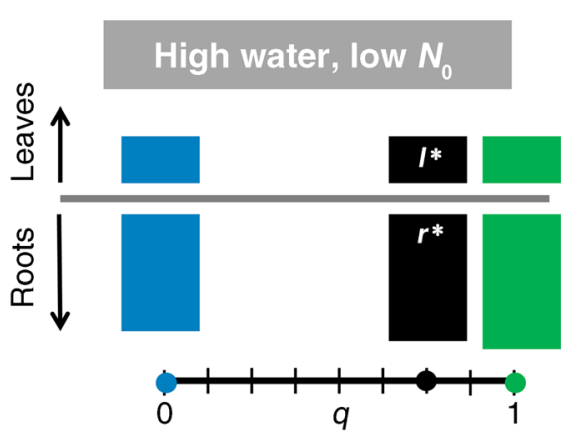

High water, high $N_{0}$

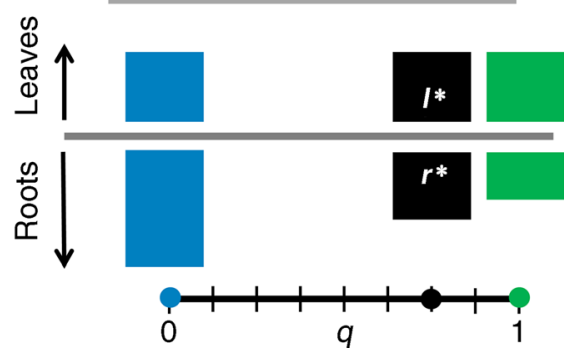

FIG. 3. The model predicts the influence of experimental water additions (increasing both time spent in water saturation $q$ and precipitation during water limitation $W$ ) on evolutionarily stable strategy (ESS) fine-root biomass $(r *)$ should become less positive or more negative as nitrogen availability increases (increasing nitrogen mineralization rate $N_{0}$; see Eq. 17). Leaf biomass $\left(l^{*}\right)$ should depend only on nitrogen (increasing with $N_{0}$ for realistic N levels; see Eq. 18). Here we depict these predictions for a range of parameter values. Please note that these parameters were not explicitly measured in the field experiment. The sizes of the blue and green boxes represent the value of ESS leaf and fine-root biomass if plants were always water limited $(q=0$, blue $)$ and if plants were always water saturated ( $q=1$, green). The ESS fine-root biomass, $r^{*}$ is a weighted combination of the blue and green boxes and is represented by the size of the black box:

$$
r^{*}=\left((1-q) \frac{\omega W_{0}}{c_{\mathrm{r}}}+q \frac{\alpha_{\mathrm{f}} L_{0} \frac{N_{0}}{\eta \rho} e^{-k\left(N_{0} / \eta \rho\right)}}{c_{\mathrm{r}}}-\left(\frac{c_{1}}{c_{\mathrm{r}}}\right)\left(\frac{N_{0}}{\rho}\right)\right) .
$$

The interaction between water and nitrogen on fine-root biomass is demonstrated by comparing rows or columns. Comparing rows shows that, at low $N_{0}$, water addition increases fine-root biomass by both the increase in the size of the blue box (increasing $W_{0}$ increases competition for water) and the weight of the green box (increasing $q$, the influence of competition for nitrogen). The effect of water addition is diminished at high $N_{0}$ because the size of the green box is smaller (competition for nitrogen decreases). Comparing columns shows that, at low water levels, the green boxes have little influence on $r^{*}$ (low $q$ ), and $N_{0}$ additions have little effect. At high water levels, the influence of the green boxes on $r^{*}$ is revealed (high $q$ ).

nitrogen co-limit plants and lead to significant waternitrogen interactions in experiments, the explanation of the decrease in root investment with nitrogen additions and the explanation for increased root investment with water additions.

The explanations from our model should not be and do not seem to be restricted to our particular experiment. The model's predictions are consistent with the results of other published factorial water and nitrogen addition experiments. For example, in a Canadian prairie, Lamb et al. (2007) finds a significant increase in belowground biomass with water additions that appears to decrease with nitrogen additions, as our model predicts. Our ability to test the model with other published studies however, is limited by the lack of belowground measurements in most factorial water and nitrogen addition experiments.

In our model, at any one moment, photosynthesis is limited by the resource in shortest supply, a concept central to Liebig's law of the minimum. Furthermore, plants act to maximize their carbon gain by investing in structures that take up those resources that are most limiting, a concept central to the multiple limitation hypothesis. We add to these concepts carbon maximization within a competitive context and the specific biological functions of water and nitrogen in plants: the dependence of plant fitness on $\mathrm{N}$ and water uptake, and the environmental variability of the supply of each 
resource relative to a plant storage ability. As a result, we found that plants were limited by a single resource at any one instant, but were limited by both over the season, a blend of limitation distinct from $\mathrm{LMH}$ and MLH.

This form of co-limitation should be pervasive in plant communities. In any place where there are rainstorms and sufficiently dry periods throughout the growing season, plants will switch between water limitation and water saturation. If nitrogen availability is high enough that plants can make several leaf layers, there is likely to be light limitation during water saturation. These components should lead to significant interactions between water and nitrogen and/or light availability in other systems and other models, whenever increasing water availability enhances the influence of the other productivity limiting resources. Evidence of interactions between water and nitrogen additions may thus be evidence of co-limitation over the course of a growing season caused by fluctuations in the identities of the limiting resources, rather than the result of a delicate balancing act that maintains colimitation at each instant during the season. This sequential co-limitation is driven by competitive optimization of resource capture in the face of fluctuations in resource availability.

\section{ACKNOWLEDGMENTS}

We thank Troy Mielke, Kally Worm, and Cedar Creek interns, especially those from the summer of 2010, for their help sampling the experiments. We thank Carla Staver, Sarah Batterman, Henry Horn, Matthew Lutz, Alexandra Wright, Lindsay Turnbull, and an anonymous reviewer for helpful comments on the manuscript, and Lars Hedin for the suggestion to consider the effect of water on nitrogen availability. This material is based upon work supported under a National Science Foundation Graduate Research Fellowship (DGE-0646086), the Carbon Mitigation Initiative (CMI), USDA Forest Service, and the National Science Foundation Long Term Ecological Research (NSF/LTER-0620652).

\section{Literature Cited}

Adler, P. B., J. HilleRisLambers, P. C. Kyriakidis, Q. Guan, and J. M. Levine. 2006. Climate variability has a stabilizing effect on the coexistence of prairie grasses. Proceedings of the National Academy of Sciences USA 103:12793-12798.

Aerts, R., R. G. A. Boot, and P. J. M. van der Aart. 1991. The relation between above- and belowground biomass allocation patterns and competitive ability. Oecologia 87:551-559.

Agren, G. I., J. A. M. Wetterstedt, and M. F. K. Billberger. 2012. Nutrient limitation on terrestrial plant growthmodeling the interaction between nitrogen and phosphorus. New Phytologist 194:953-960.

Bloom, A. J., F. S. Chapin, III, and H. A. Mooney. 1985. Resource limitation in plants - an economic analogy. Annual Review of Ecology and Systematics 16:363-392.

Borken, W., and E. Matzner. 2009. Reappraisal of drying and wetting effects on $\mathrm{C}$ and $\mathrm{N}$ mineralization and fluxes in soils. Global Change Biology 15:808-824.

Chapin, F. S., III, 1980. The mineral nutrition of wild plants. Annual Review of Ecology and Systematics 11:233-260.

Chapin, F. S., III, A. J. Bloom, C. B. Field, and R. H. Waring. 1987. Plant responses to multiple environmental factors: physiological ecology provides tools for studying how interacting environmental resources control plant growth. BioScience 37:49-57.

Collatz, G. J., J. T. Ball, C. Grivet, and J. A. Berry. 1991. Physiological and environmental regulation of stomatal conductance, photosynthesis and transpiration: a model that includes a laminar boundary layer. Agricultural and Forest Meteorology 54:107-136.

Craine, J. M. 2006. Competition for nutrients and optimal root allocation. Plant and Soil 285:171-185.

Craine, J. M., J. Fargione, and S. Sugita. 2005. Supply preemption, not concentration reduction, is the mechanism of competition for nutrients. New Phytologist 166:933-940.

Danger, M., T. Daufresne, F. Lucas, S. Pissard, and G. Lacroix. 2008. Does Liebig's law of the minimum scale up from species to communities? Oikos 117:1741-1751.

Dybzinski, R., C. Farrior, A. Wolf, P. B. Reich, and S. W. Pacala. 2011. Evolutionarily stable strategy carbon allocation to foliage, wood, and fine roots in trees competing for light and nitrogen: an analytically tractable, individual-based model and quantitative comparisons to data. American Naturalist 177:153-166.

Evans, J. R., and H. Poorter. 2001. Photosynthetic acclimation of plants to growth irradiance: the relative importance of specific leaf area and nitrogen partitioning in maximizing carbon gain. Plant, Cell and Environment 24:755-767.

Falster, D., and M. Westoby. 2003. Plant height and evolutionary games. Trends in Ecology and Evolution 18: 337-343.

Farquhar, G. D., S. von Caemmerer, and J. A. Berry. 2001. Models of photosynthesis. Plant Physiology 125:42-45.

Farrior, C. E., R. Dybzinski, S. A. Levin, and S. W. Pacala. 2013. Competition for water and light in closed-canopy forests: a tractable model of carbon allocation with implications for carbon sinks. American Naturalist 181: 314-330.

Frank, D. A., A. W. Pontes, E. M. Maine, J. Caruana, R. Raina, S. Raina, and J. D. Fridley. 2010. Grassland root communities: species distributions and how they are linked to aboveground abundance. Ecology 91:3201-3209.

Gedroc, J. J., K. D. M. McConnaughay, and J. S. Coleman. 1996. Plasticity in root/shoot partitioning: optimal, ontogenetic, or both? Functional Ecology 10:44-50.

Geritz, S. A. H., E. Kisdi, G. Meszena, and J. A. J. Metz. 1998. Evolutionarily singular strategies and the adaptive growth and branching of the evolutionary tree. Evolutionary Ecology 12:35-57.

Givnish, T. J. 1982. On the adaptive significance of leaf height in forest herbs. American Naturalist 120:353-381.

Gleeson, S. K., and D. Tilman. 1992. Plant allocation and the multiple limitation hypothesis. American Naturalist 139: $1322-1343$.

Hardin, G. 1968. The tragedy of the commons. Science 162: $1243-1248$

Harpole, W. S., et al. 2011. Nutrient co-limitation of primary producer communities. Ecology Letters 14:852-862.

Iwasa, Y., D. Cohen, and J. A. Leon. 1984. Tree height and crown shape, as results of competitive games. Journal of Theoretical Biology 112:279-297.

Kaspari, M., M. N. Garcia, K. E. Harms, M. Santana, S. J. Wright, and J. B. Yavitt. 2008. Multiple nutrients limit litterfall and decomposition in a tropical forest. Ecology Letters 11:35-43.

King, D. A. 1990. The adaptive significance of tree height. American Naturalist 135:809-828.

Lamb, E. G., B. H. Shore, and J. F. Cahill. 2007. Water and nitrogen addition differentially impact plant competition in a native rough fescue grassland. Plant Ecology 192:21-33.

Larcher, W. 2003. Physiological plant ecology: ecophysiology and stress physiology of functional groups. Springer, New York, New York, USA. 
Lloyd, J., and G. D. Farquhar. 1996. The $\mathrm{CO}_{2}$ dependence of photosynthesis, plant growth responses to elevated atmospheric $\mathrm{CO} 2$ concentrations and their interaction with soil nutrient status. I. General principles and forest ecosystems. Functional Ecology 10:4-32.

Luo, Y., et al. 2004. Progressive nitrogen limitation of ecosystem responses to rising atmospheric carbon dioxide. BioScience 54:731-739.

Maina, G. G., J. S. Brown, and M. Gersani. 2002. Intra-plant versus inter-plant root competition in beans: avoidance, resource matching or tragedy of the commons. Plant Ecology 160:235-247.

Maynard Smith, J. 1982. Evolution and the theory of games. Cambridge University Press, Cambridge, UK.

Maynard Smith, J., and G. R. Price. 1973. The logic of animal conflict. Nature 246:15-18.

McNickle, G. G., and R. Dybzinski. 2013. Game theory and plant ecology. Ecology Letters 16:545-555.

Montgomery, R. A., P. B. Reich, and B. J. Palik. 2010. Untangling positive and negative biotic interactions: views from above and below ground in a forest ecosystem. Ecology 91:3641-55.

Oren, R., et al. 2001. Soil fertility limits carbon sequestration by forest ecosystems in a $\mathrm{CO}_{2}$-enriched atmosphere. Nature 411: 469-472.

Postel, S. P., G. C. Daily, and P. R. Ehrlich. 1996. Human appropriation of renewable fresh water. Science 271:785-788.

R Development Core Team. 2009. R 2.9.2. R Project for Statistical Computing, Vienna, Austria. www.r-project.org

Raynaud, X., and P. W. Leadley. 2004. Soil characteristics play a key role in modeling nutrient competition in plant communities. Ecology 85:2200-2214.

Reich, P. B., S. E. Hobbie, T. Lee, D. S. Ellsworth, J. B. West, D. Tilman, J. M. H. Knops, S. Naeem, and J. Trost. 2006. Nitrogen limitation constrains sustainability of ecosystem response to $\mathrm{CO}_{2}$. Nature 440:922-925.

Rubio, G., J. Zhu, and J. P. Lynch. 2003. A critical test of the two prevailing theories of plant response to nutrient availability. American Journal of Botany 90:143-152.
SAS Institute. 2012. JMP version 10. SAS Institute, Cary, North Carolina, USA.

Schimel, D. S., B. H. Braswell, R. McKeown, D. S. Ojima, W. J. Parton, and W. Pulliam. 1996. Climate and nitrogen controls on the geography and timescales of terrestrial biogeochemical cycling. Global Biogeochemical Cycles 10: 677-692.

Semchenko, M., K. Zobel, and M. J. Hutchings. 2010. To compete or not to compete: an experimental study of interactions between plant species with contrasting root behaviour. Evolutionary Ecology 24:1433-1445.

Sinclair, T. R. 1992. Mineral nutrition and plant growth response to climate change. Journal of Experimental Botany 43:1141-1146.

Slatyer, R. O. 1967. Plant-water relationships. Academic Press, London, UK.

Tilman, D. 1982. Resource competition and community structure. Princeton University Press, Princeton, New Jersey, USA.

Tilman, D. 1988. Plant strategies and the dynamics and structure of plant communities. Princeton University Press, Princeton, New Jersey, USA.

van der Ploeg, R. R., W. Bohm, and M. B. Kirkham. 1999. On the origin of the theory of mineral nutrition of plants and the law of the minimum. Soil Science Society of America Journal 63:1055-1062.

Vitousek, P. M., J. D. Aber, R. W. Howarth, G. E. Likens, P. A. Matson, D. W. Schindler, W. H. Schlesinger, and D. G. Tilman. 1997. Human alteration of the global nitrogen cycle: Sources and consequences. Ecological Applications 7:737750 .

Wilson, S. D., and D. Tilman. 1991. Component of plant competition along an experimental gradient of nitrogen availability. Ecology 72:1050-1065.

Wright, I. J., P. B. Reich, and M. Westoby. 2003. Least-cost input mixtures of water and nitrogen for photosynthesis. American Naturalist 161:98-111.

\section{Supplemental Material}

Appendix A

Experiment sampling methods: separation of aboveground biomass (Ecological Archives E094-230-A1).

\section{Appendix B}

Relaxation of territoriality and well-mixed assumptions (Ecological Archives E094-230-A2).

\section{Appendix C}

Photosynthetic rate dependence on leaf and fine-root biomass (Ecological Archives E094-230-A3).

\section{Appendix D}

Pairwise invasion plot (Ecological Archives E094-230-A4). 